\section{In celebration of medical essayists}

\author{
John Launer
}

This month, the Postgraduate Medical Journal celebrates its 90th anniversary. By a nice coincidence, this happens to be the 90th article I have contributed to its pages, mainly in the form of reflective essays in this column. I feel privileged to be associated with the journal, and to be following in the footsteps of Sir William Osler, who helped to found the Fellowship of Postgraduate Medicine, became its first president, and was one of the greatest medical essayists of all time. It seems an appropriate moment to celebrate the place of the essay in medical journalism, and to pay tribute to some of its most distinguished practitioners. As Osler demonstrated, it is essays that put the flesh of medical dialogue and debate on the bare bones of science. Although medical journals publish a great deal of original research, most of them also include more discursive articles on wider topics, including politics, ethics and clinical controversies. Often, the other parts of a journal, including editorials, reviews, letters and case descriptions are written in essay form too. In many ways, the essay therefore is the defining form of medical writing.

The essay is part of a wider culture than medicine, and it goes back a long way. The French philosopher Michel de Montaigne defined the literary form in the sixteenth century, with his own collection, entitled simply 'Essays'. These were delightful reflections on human affairs, psychology, writing and just about any topic under the sun that caught his fancy. Later on, great English essayists including Joseph Addison and Samuel Johnson set up periodicals like the Spectator, and essays have formed the backbone of such publications ever since. Many great novelists, including George Orwell and Mark Twain, became famous for their essay-writing as much as for their books. The same is true of some historians and philosophers.

In medicine, the physician Sir Thomas Browne began a distinguished tradition of essays with 'Religio Medici' in 1642. From then onwards, until the emergence of the standardised research article in the middle of the 20th century, medical knowledge was

Correspondence to Dr John Launer, Faculty Development, Health Education England, Stewart House, 32 Russell Square, London WC1B 5DN, UK: john.launer@nwl.hee.nhs.uk generally presented in essay form, as vintage issues of the $P M J$ make clear. My own favourite medical essayist has always been Richard Asher. He was a physician at the Central Middlesex Hospital during the 1950s and 60s. His classic articles included 'The dangers of going to bed', 1 'Myxoedematous madness' 2 and 'Why are medical journals so dull?'. ${ }^{3}$ They are all masterpieces of clear writing and common sense. He also offered a model of how to make an essay punchy and funny, while at the same time being accurate, humane and pragmatic. He influenced the entire next generation of great essayists, including Michael O'Donnell, who edited a wonderfully irreverent magazine called World Medicine. Following that magazine's demise in the $1980 \mathrm{~s}$, many people predicted that the printed medical essay would soon die out, especially given the prodigious amount of research that doctors were expected to read and write, and the limited time this left doctors for so-called 'light reading'.

\section{GOLDEN AGE}

In fact, the opposite has turned out to be the case, and the last few decades have turned out to be something of a golden age for essayists and columnists. The complexities of modern medicine, the pressure of organisational change, and the sheer volume of information available, seem to have increased the need for writers who can see the wood for the trees and help colleagues to see their work in proportion. Among other notable essayists, Iona Heath, a recent president of the Royal College of General Practitioners, stands out as someone who has often applied her writing with passion, to inveigh against medical overdiagnosis, health inequality and social injustice. ${ }^{4}$ Another writer, "Tony Copperfield" (a pseudonym for a doctor who keeps his true identity a secret) regularly satirises his colleagues, by expressing views of outrageous and hilarious political incorrectness. $^{5}$

However, it is the internet, social media and in particular blogs that have most transformed the art of the medical essayist. When people asked me ten years ago how to break into the world of medical writing, I could only advise them to send unsolicited proposals or drafts to editors, and keep their fingers crossed for a response. This was rather like telling them to put a message in a bottle and throw it into the ocean. Nowadays, there is no need to bother with this. Anyone can launch themselves as a writer on the worldwide web. From the feedback they get (or its absence), they will find out very soon whether people consider their writing to be as witty and wise as they hope. There is a vast market of potential readers, and some of these work on journals or are editors. You can be 'discovered' quite quickly, and taken on as a regular blogger. It is easy to find out who the successful bloggers are, and to see what it is about their style and content that makes them readable. If you don't already follow the PMJ's own blogger, Toby Hillman, you should do so. ${ }^{6}$ Our sister journal The BMJ also has a stable that includes many excellent bloggers: I would particularly recommend Richard Lehmann, who publishes an extraordinarily literate blog every week, reviewing the latest medical research and throwing in some gardening tips for good measure.

If you enjoy writing, like to keep a journal, or even just love to send long letters and emails to friends, I would strongly recommend the pleasures of writing essays for a medical audience. It will help you to frame your own ideas and opinions more precisely, stimulate debate with others, build friendships with colleagues near and far, establish a record of your own development as a professional, and contribute to the advancement of medical practice. You may even make a small amount of income from it. It will also mean that a journal like the $P M J$ continues to thrive into the twentysecond century, and remains as informative and engaging as it is now.

Twitter Follow John Launer at @JohnLauner

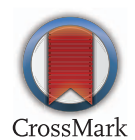

To cite Launer J. Postgrad Med J 2015;91:608.

Postgrad Med J 2015;91:608.

doi:10.1136/postgradmedj-2015-133717

\section{REFERENCES}

1 Asher RAJ. The dangers of going to bed. Br Med J 1947;2:967.

2 Asher R. Myxoedematous madness. Br Med 1 1949;2:555-62.

3 Asher R. Why are medical journals so dull? Br Med J 1958:2:502-3.

4 Heath I. Matters of Life and Death: Key Writings. Abingdon: Radcliffe Publishing, 2007.

5 Copperfield T. Sick Notes: A Doctor's Tales from the Front Lines of Medicine. Cheltenham: Monday Books, 2010.

6 Hillman T. Postgraduate Medical Journal blog. Postgrad Med J http://blogs.bmj.com/pmj/

7 Lehman R. Weekly review of medical journals. The BMJ http://blogs.bmj.com/bmj/category/richardlehmans-weekly-review-of-medical-journals/ 